\title{
Preparation of highly active zinc oxide for photocatalytic removal of phenol: Direct calcination versus co-precipitation method
}

\author{
Faisal Hussin ${ }^{1}$, Hendrik O. Lintang ${ }^{2}$, Siew Ling Lee ${ }^{2}$, Leny Yuliati ${ }^{2 *}$ \\ ${ }^{1}$ Department of Chemistry, Faculty of Science, Universiti Teknologi Malaysia, 81310 UTM Johor Bahru, Johor, Malaysia. \\ ${ }^{2}$ Centre for Sustainable Nanomaterials, Ibnu Sina Institute for Scientific and Industrial Research, Universiti Teknologi Malaysia, 81310 UTM Johor Bahru, \\ Johor, Malaysia. \\ *Corresponding Author: leny@ibnusina.utm.my
}

\section{Article history :}

Received 1 November 2015

Accepted 13 November 2015

\section{GRAPHICAL ABSTRACT}

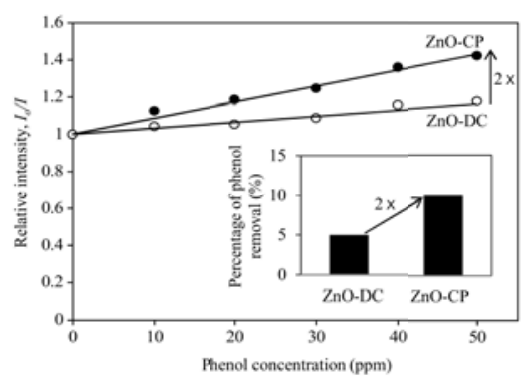

\section{ABSTRACT}

Photocatalytic removal of phenol under UV light irradiation was studied on zinc oxide $(\mathrm{ZnO})$ photocatalysts, which were prepared via direct calcination (DC), and co-precipitation (CP) methods. The XRD patterns revealed that all of the prepared $\mathrm{ZnO}$ samples showed wurtzite structure, in which the $\mathrm{ZnO}-\mathrm{CP}$ showed higher intensity of the diffraction peaks than the $\mathrm{ZnO}-\mathrm{DC}$ sample. Optical and fluorescence properties of the prepared $\mathrm{ZnO}$ samples were similar to each other as confirmed by $\mathrm{DR}$ UV-Vis and fluorescence spectroscopy, respectively. The Stern-Volmer plot was investigated to study the interactions between the emission sites and the phenol. It was obtained that the emission sites of the $\mathrm{ZnO}-\mathrm{CP}$ gave better interactions towards phenol molecules as compared to the $\mathrm{ZnO}-\mathrm{DC}$. After 6 hours reaction under $\mathrm{UV}$ light irradiation, the $\mathrm{ZnO}-\mathrm{CP}$ sample showed two times higher photocatalytic activity for removal of phenol $(10 \%)$ than that of the $\mathrm{ZnO}-\mathrm{DC}(5 \%)$. It was suggested that the high activity observed on the $\mathrm{ZnO}-\mathrm{CP}$ sample would be due to high crystallinity and good interactions with phenol. These results clearly suggested that the co-precipitation method was a good approach to prepare the highly active $\mathrm{ZnO}$ for the photocatalytic removal of phenol.

Keywords: $\mathrm{ZnO}$, co-precipitation, UV-light irradiation, phenol, photocatalyst

\section{INTRODUCTION}

Phenol is an example of the aromatic pollutants that is often encountered in the environment as an effluent of industrial wastewater in the trace quantities. The toxicity of phenol needs to be considered nowadays since its toxicity can lead to serious injury and fatal death during exposure to phenol for a long period time. Phenol is also stable, hardly to be decomposed and remains for a long period time in environment. According to Central Pollution Control Board, the protection rules in discharge limits of phenols in water are only $1 \mathrm{mg} / \mathrm{L}$ and more to this value will lead to immediate dangerous to life or health [1]. Recently, many studies have been conducted with focus on the green approach to treat organic pollutants using photocatalytic reaction [2-4].

Heterogeneous photocatalytic reactions using powder semiconductor have been studied for decades, which discovery was reported by Honda and Fujishima in 1972 [5]. The heterogeneous photocatalytic process is initiated when a photocatalyst receives a photon with energy equal or greater than its band gap energy $\left(E_{\mathrm{bg}}\right)$, resulting in the generation of mobile electrons in the conduction band $\left(E_{\mathrm{cb}}\right)$ and positive holes in the valence band $\left(E_{\mathrm{vb}}\right)$ of the photocatalyst. The photocatalytic reaction proceeds via a series of chemical process, through the formation of holes for oxidation processes, the generation of electrons for reduction processes, as well as the formation of superoxide anions and radical hydroxide ion from oxygen. The unstable radical hydroxide ion tends to attract electrons from nearby organic compound which causes the targeted organic compounds lose their electron and start to decompose, forming non-hazardous compounds such as carbon dioxide and water [6].

Zinc oxide $(\mathrm{ZnO})$ as one of metal oxide semiconductors has received a lot of attention due to its unique properties of wide band gap energy $(3.37 \mathrm{eV})$, nontoxic, and its higher photocatalytic efficiency as compared to $\mathrm{TiO}_{2}$ in photocatalytic degradation of organic dyes $[7,8]$. The efficiency of the photocatalytic processes depended on several characteristic properties such as the position of the band gap potentials, recombination rate of charge carriers 
generated by light sources and surface properties of the photocatalyst [9]. However, only few studies have been carried out to clarify the dominant factors for the enhancement of photocatalytic degradation of organic pollutants. In this work, the effect of synthesis methods on the properties and photocatalytic activities of the $\mathrm{ZnO}$ was investigated. Two different methods to synthesize $\mathrm{ZnO}$ were employed, which were direct calcination and coprecipitation methods.

\section{EXPERIMENTS}

\subsection{Photocatalyst Preparations}

2.1.1 Preparation of $\mathrm{ZnO}$ by direct calcination method (ZnO-DC)

For preparation of $\mathrm{ZnO}-\mathrm{DC}$, the $\mathrm{Zn}\left(\mathrm{CH}_{3} \mathrm{COO}\right)_{2} .2 \mathrm{H}_{2} \mathrm{O}(4.5 \mathrm{~g})$ as the precursor was ground finely and the solid was then calcined at $550{ }^{\circ} \mathrm{C}$ at a rate of $1.0^{\circ} \mathrm{C} / \mathrm{min}$ and tempered for $1 \mathrm{~h}$ at this temperature.

2.1.2 Preparation of $\mathrm{ZnO}$ by co-precipitation method ( $\mathrm{ZnO}-\mathrm{CP})$

For preparation of $\mathrm{ZnO}-\mathrm{CP}$, it was adopted from the previous reported literature [10]. The $\mathrm{Zn}\left(\mathrm{CH}_{3} \mathrm{COO}\right)_{2} \cdot 2 \mathrm{H}_{2} \mathrm{O}$ $(4.5 \mathrm{~g})$ was dissolved in deionized water $(100 \mathrm{~mL})$ and sonicated for $30 \mathrm{~min}$ to obtain solution A. For preparation of solution $\mathrm{B}, \mathrm{NaOH}(6.4 \mathrm{~g})$ was dissolved in deionized water $(100 \mathrm{~mL})$ and $\mathrm{C}_{19} \mathrm{H}_{42} \mathrm{BrN}(7.28 \mathrm{~g})$ was added into the mixture and stirred for $1 \mathrm{~h}$ to obtain a homogeneous solution. Solution A was added slowly into solution B, followed by heating at $70{ }^{\circ} \mathrm{C}$ for $1 \mathrm{~h}$. The remaining solid was then filtered and washed with deionized water and ethanol, consecutively. The solid powder was dried and then calcined at $500{ }^{\circ} \mathrm{C}$ at a rate of $1.0{ }^{\circ} \mathrm{C} / \mathrm{min}$ and tempered for $1 \mathrm{~h}$ at this temperature.

\subsection{Photocatalyst Characterizations}

X-ray Diffraction (XRD, Bruker AXS Diffrac plus release 2000) was used to identify the structure of the prepared photocatalysts. The X-ray diffractogram of the catalyst was analyzed at $2 \theta$ range of $10-75^{\circ}$ with scan rate of $0.05^{\circ} \mathrm{s}^{-1}$.The diffuse reflectance UV-Visible (DR UVVis, Shimadzu UV-2600) was used to identify the optical properties of the prepared photocatalysts. The fluorescence spectroscopy (JASCO Spectrofluorometer FP-8500) was used to obtain emission spectra of samples. The spectra were monitored at wavelength $277 \mathrm{~nm}$ for excitation spectra and $218 \mathrm{~nm}$ for emission spectra measurements. For quenching test, various range amounts of phenol solution using acetonitrile as a solvent $(10-50 \mathrm{ppm}, 10 \mathrm{u} \mathrm{L})$ were introduced to the $\mathrm{ZnO}-\mathrm{DC}$ and $\mathrm{ZnO}-\mathrm{CP}$ samples. The emission spectra were then measured directly at excitation wavelength of $218 \mathrm{~nm}$.

\subsection{Photocatalytic Tests}

The photocatalytic removal of phenol was conducted at room temperature. The photocatalyst $(50 \mathrm{mg})$ was dispersed in $100 \mathrm{~mL}$ of jacketed-beaker containing of phenol solution using acetonitrile as a solvent (10 ppm, 25 $\mathrm{mL}$ ). Then, the beaker was placed on a stirring plate with cooling water system in a closed box for 30 minutes to let the adsorption reach the equilibrium. The reaction was carried out for 6 hours under UV light irradiation. After reaction, the solution was taken and separated from the photocatalyst. The remaining phenol was measured by Gas Chromatography equipped with Flame Ionization Detector (GC-FID, Agilent 7820A). The percentage of phenol removal was calculated by the equation (1) below.

$X_{\text {phenol }}(\%)=\frac{\mathrm{C}_{0}-\mathrm{C}}{\mathrm{C}_{0}} \times 100 \%$

Where $X_{\text {phenol }}$ is the amount of phenol removal (\%), $C_{0}$ is the initial concentration of phenol in solution before reaction and $C$ is final concentration of phenol in solution after photocatalytic reaction.

\section{RESULTS AND DISCUSSION}

Figure 1 shows theXRD patterns ofZnO-DC and $\mathrm{ZnO}-\mathrm{CP}$ samples. All of the synthesized $\mathrm{ZnO}$ samples showed the typical diffraction pattern of $\mathrm{ZnO}$ which can be indexed as a wurtzite structure [10-11]. The observed peaks corresponded to (100), (002), (101), (102), (100), (103), (103), (112), (101) and (201) with (101) plane is the most prominent one. Despite of the lower calcination temperature, it was obvious that the $\mathrm{ZnO}-\mathrm{CP}$ sample showed more intense peaks than the $\mathrm{ZnO}-\mathrm{DC}$, suggesting that $\mathrm{ZnO}-\mathrm{CP}$ showed a higher crystallinity than the $\mathrm{ZnO}$ DC. The crystallite size of the prepared samples was calculated by using a Scherrerequation shown in the equation (2), based on the most prominent peak of (101) plane.

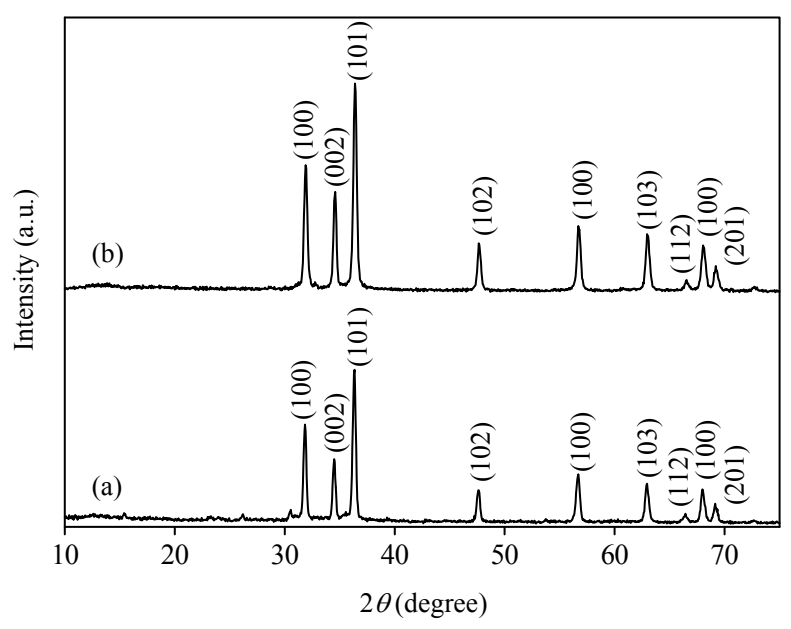

Fig. 1 XRD patterns of (a) ZnO-DC and (b) ZnO-CP 


$$
D=\frac{0.9 \lambda}{\beta \cos \theta}
$$

where $\lambda$ is the $\mathrm{X}$-ray wavelength of $\mathrm{Cu} \mathrm{K}_{\alpha}$ radiations, $\beta$ is the line broadening full width at half the maximum intensity and $\theta$ is the angle obtained from $2 \theta$ that is corresponding to the maximum intensity peak in the XRD pattern. The mean crystallite size of the prepared $\mathrm{ZnO}$ samples was determined to be 17.47 and $19.43 \mathrm{~nm}$ for the $\mathrm{ZnO}-\mathrm{DC}$ and the $\mathrm{ZnO}-\mathrm{CP}$, respectively.

The DR UV-Vis spectra of the ZnO-DC and the $\mathrm{ZnO}-\mathrm{CP}$ are shown in Fig. 2. Both $\mathrm{ZnO}$ samples showed similar characteristics, where they exhibited a wide absorption range at the $\mathrm{UV}$ region. The $\mathrm{ZnO}-\mathrm{DC}$ and the $\mathrm{ZnO}-\mathrm{CP}$ showed the similar absorption peak centered at $320 \mathrm{~nm}$, which corresponded to the formation of $\mathrm{ZnO}$. The absorption edge for both samples were also similar to each other, which was up to $390 \mathrm{~nm}$, suggesting the similar band gap energy on these samples.

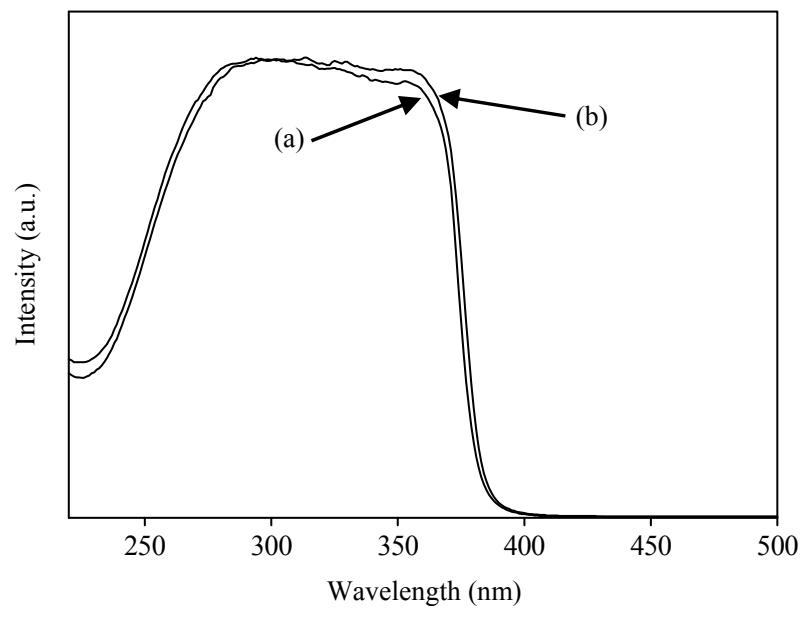

Fig. 2 Normalized DR UV-Vis spectra of (a) ZnO-DC and (b) $\mathrm{ZnO}-\mathrm{CP}$

Fig. 3 shows the fluorescence spectra of $\mathrm{ZnO}-\mathrm{DC}$ and $\mathrm{ZnO}-\mathrm{CP}$ samples. The excitation spectra were monitored at emission wavelength of $276 \mathrm{~nm}$, while the emission spectra were monitored at excitation wavelength of $218 \mathrm{~nm}$.It has been generally proposed that the intensity of the emission spectra is related to the electron-hole recombination. As can be seen in Fig. 3, the $\mathrm{ZnO}-\mathrm{CP}$ showed lower emission intensity than the $\mathrm{ZnO}-\mathrm{DC}$ suggesting that the electron-hole recombination on the $\mathrm{ZnO}-\mathrm{CP}$ was lower than that on the $\mathrm{ZnO}-\mathrm{DC}[12]$.

In order to investigate the interactions between the emission sites and phenol molecules, quenching study was performed by adding various concentrations of phenol to the $\mathrm{ZnO}-\mathrm{DC}$ and $\mathrm{ZnO}-\mathrm{CP}$. As shown in Fig. 4 [A], the addition of phenol solution reduced the emission intensity of both $\mathrm{ZnO}-\mathrm{DC}$ and $\mathrm{ZnO}-\mathrm{CP}$. The emission intensity was more reduced with the higher concentration of the phenol. The significance drop of emission intensity was observed when $10 \mathrm{ppm}$ of phenol was added to the sample as compared to larger concentration of phenol which would be due to the active sites of both $\mathrm{ZnO}-\mathrm{DC}$ and $\mathrm{ZnO}-\mathrm{CP}$ available were immensely used to interact with phenol during addition of $10 \mathrm{ppm}$ phenol and only few remaining active sites were available for larger concentration of phenol. Stern-Volmer plot was used to analyze the interactions based on the equation (3) below [13].

$\frac{I o}{I}=K_{S v}[Q]+1$

where $I_{o}$ and $I$ are fluorescence intensities observed in the absence and presence of phenol, respectively, $Q$ is the phenol concentration and $K_{s v}$ is the Stern-Volmer plot quenching constant. As shown in Figure 4 [B], the $\mathrm{ZnO}-\mathrm{CP}$ showed higher $K_{s v}$ value $\left(0.008 \mathrm{ppm}^{-1}\right)$ than that of the $\mathrm{ZnO}-\mathrm{DC}\left(0.003 \mathrm{ppm}^{-1}\right)$. This result obviously suggested the capability of the $\mathrm{ZnO}-\mathrm{CP}$ to interact with phenol was more than two times higher than the $\mathrm{ZnO}-\mathrm{DC}$. Since the photocatalytic reactions depend strongly on the interactions with the target pollutants [14], the higher the interactions with phenol would give higher photocatalytic activity for the $\mathrm{ZnO}-\mathrm{CP}$ towards removal of phenol.

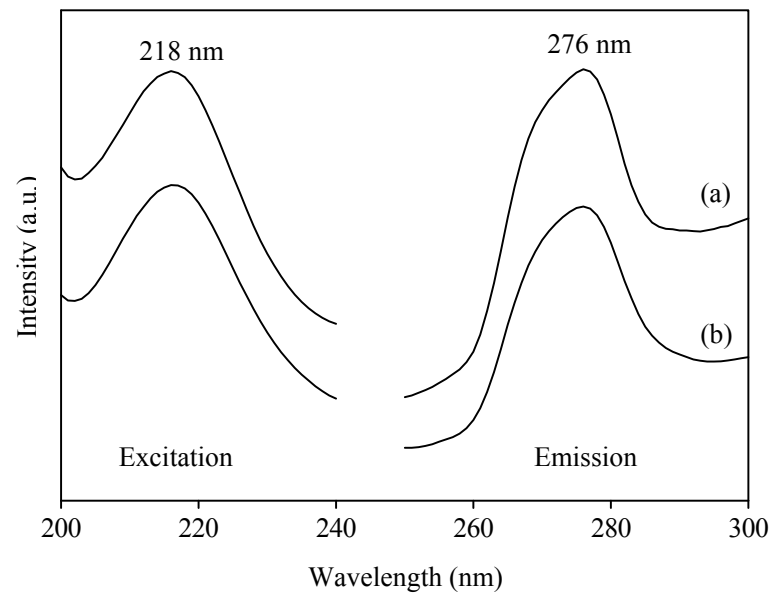

Fig. 3 Excitation and emission spectra of (a) ZnO-DC and (b) $\mathrm{ZnO}-\mathrm{CP}$

Fig. 5 shows the photocatalytic activity of the $\mathrm{ZnO}$ $\mathrm{DC}$ and the $\mathrm{ZnO}-\mathrm{CP}$ samples for the removal of phenol. It was obtained that the $\mathrm{ZnO}-\mathrm{CP}$ showed higher photocatalytic activity $(10 \%)$ than the $\mathrm{ZnO}-\mathrm{DC}(5 \%)$. It has been generally reported that the crystallinity of photocatalyst played important role to give high photocatalytic activity $[15,16]$. In the present study, the higher activity of the $\mathrm{ZnO}-\mathrm{CP}$ than the $\mathrm{ZnO}-\mathrm{DC}$ would be due to the higher crystallinity, which led to the less electron-hole recombination as also supported by the emission spectra. The highly crystalline materials showed relatively lower density of defects caused by ground boundaries, which act as recombination centre for electrons and holes [17]. The presence of recombination centre promotes fast electron-hole recombination which prevents 
effective chemical processes during photocatalytic reaction, thus lowering the photocatalytic activity.
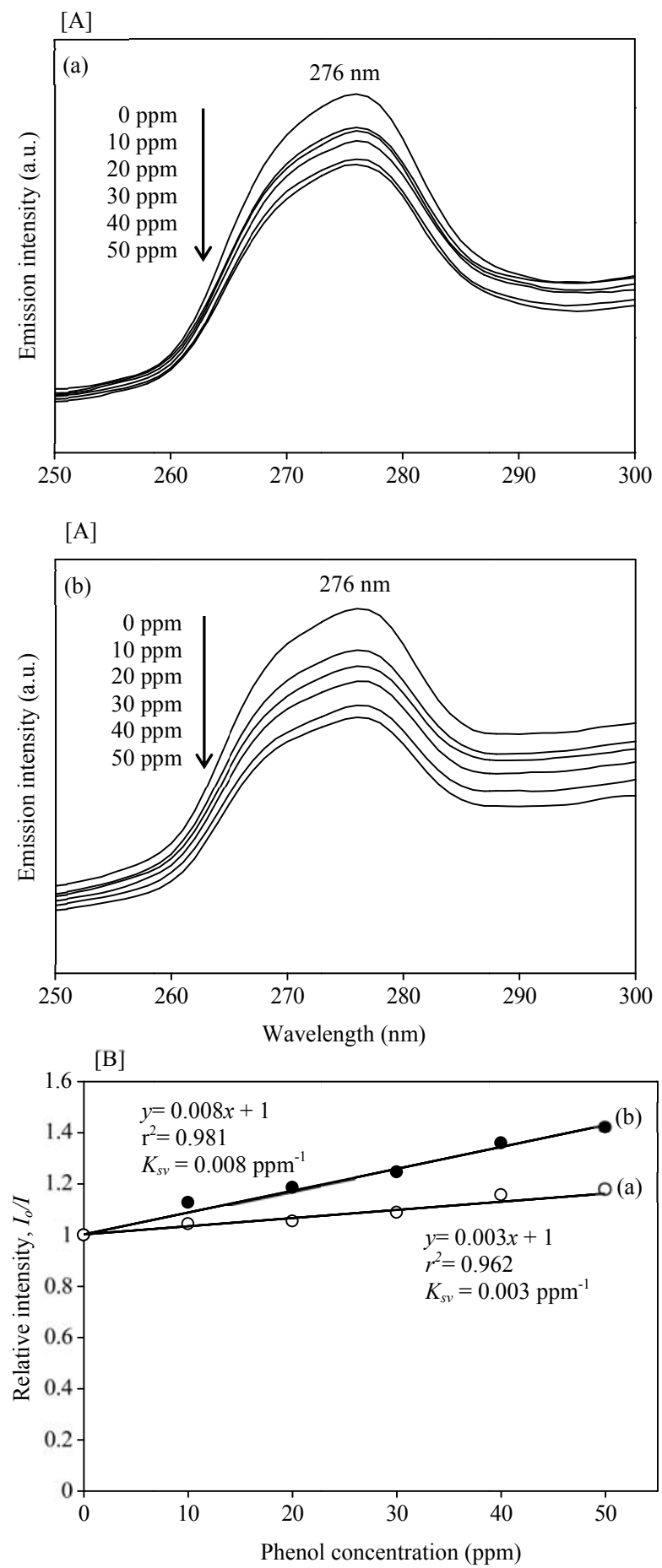

Fig. 4 [A] Reduced emission intensity in the presence of phenol with various concentrations on (a) $\mathrm{ZnO}-\mathrm{DC}$ and (b) $\mathrm{ZnO}-\mathrm{CP}$, and [B] Stern-Volmer plots of (a) ZnO-DC and (b) ZnO-CP

Another reason for the higher activity would be the better interactions observed between the $\mathrm{ZnO}-\mathrm{CP}$ and phenol than the $\mathrm{ZnO}-\mathrm{DC}$ and phenol, which was supported with the adsorption test on both $\mathrm{ZnO}-\mathrm{CP}(2 \%)$ and $\mathrm{ZnO}$ -
DC (1\%). As shown in Fig. 4 [B], the $\mathrm{ZnO}-\mathrm{CP}$ gave more than two times higher quenching rate constant, suggesting that the interactions with phenol molecules would be also two times more than the $\mathrm{ZnO}-\mathrm{DC}$. These results obviously showed that these two factors would be the important factors that result in the high photocatalytic activity towards the removal of phenol.

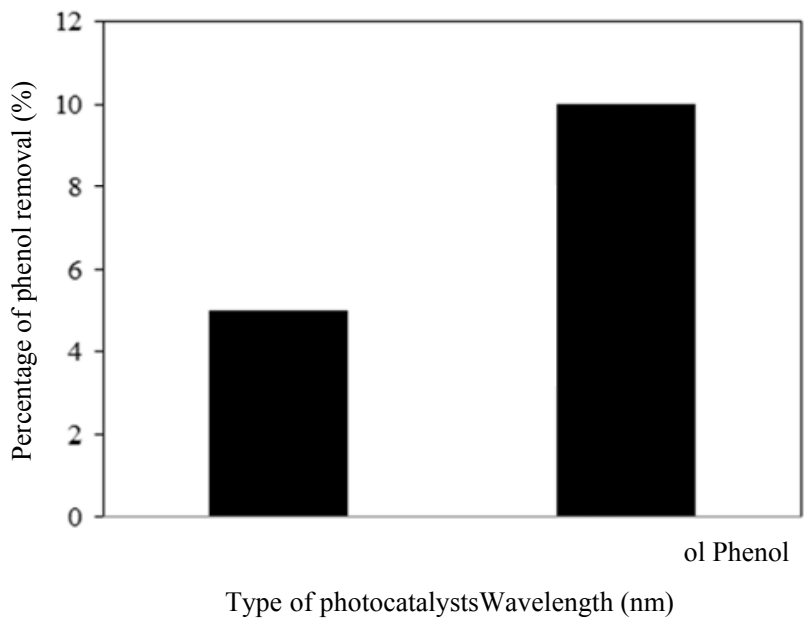

Fig. 5 Percentage of phenol removal on the $\mathrm{ZnO}-\mathrm{DC}$ and the $\mathrm{ZnO}-\mathrm{CP}$ after 6 hours reaction under $\mathrm{UV}$ light irradiation

\section{CONCLUSION}

The $\mathrm{ZnO}$ photocatalysts can be synthesized successfully by direct calcination and co-precipitation methods. The $\mathrm{ZnO}$ sample prepared by the co-precipitation method showed $c a$. two times higher activity than the $\mathrm{ZnO}$ sample prepared by direct calcination method. The enhancement of photocatalytic activity on the $\mathrm{ZnO}-\mathrm{CP}$ sample was caused by the high crystallinity that led to the reduced electron-hole recombination, and good interactions with the phenol.

\section{ACKNOWLEDGEMENTS}

The work was financially supported by the Ministry of Higher Education (MOHE, Malaysia) and the Universiti Teknologi Malaysia (UTM, Malaysia) through a Tier-1 Research University Grant (cost center code: Q.J130000.2509.06H66). F. H. acknowledges the support of UTM through Zamalah Scholarships.

\section{REFERENCES}

[1] S. Latasree, A.N. Rao, B. Sivasankar, V. Sadasivam,K.Rengaraj, J. Mol.Catal. A: Chem. 223 (2004) 101.

[2] Y. Bessekhouad, D. Robert, J.V. Weber, J. Photochem. Photobiol. A. 163 (2004) 569.

[3] X. He, Y. Cai, H. Zhang, C. Liang, J. Mater. Chem. 21 (2011) 475.

[4] Y. Lin, D. Li, J. Hu, G. Xiao, J. Wang, W. Li, X. Fu, J. Phys. Chem. 116 (2012) 5764.

[5] A. Fujishima, K. Honda, Nature 238 (1972) 37. 
[6] S. Ahmed, M.G. Rasul, W.N. Martens, R. Brown, M.A. Hashib, Desalination $261(2010) 3$.

[7] I.A. Khattab, M.Y. Ghaly, L. Österlund, M.E.M. Ali, J.Y. Farah, F.M. Zaher, M.I. Badawy, Desalin. Water Treat. 48 (2012) 120.

[8] S.O. Fatin, H.N. Lim, W.T. Tan, N.M. Huang, Int. J. Electrochem. Sci. 7 (2012) 9074.

[9] J. Wang, X. Liu, R. Li, P. Qiao, L. Xiao, J. Fan, Catal. Commun.19 (2012) 96.

[10] S. Suwanboon, P. Amornpitoksuk, S. Muensit, J. Ceram. Process. Res. 11 (2010) 419.

[11] S. Bai, J. Hu, D. Li, R. Luo, A. Chen, C.C. Liu, J. Mater. Chem. 21 (2011) 12288.
[12] S. Wu, H. Zheng, Y. Lian, Y. Wu, Mater. Res. Bul. 48 (2013) 2901.

[13] M.S. Sam, H.O. Lintang, M.M. Sanagi, S.L. Lee, L. Yuliati, Spectrochim. Acta, Part A. 124 (2014) 357.

[14] D. Zhao, C. Chen, Y. Wang, W. Ma, J. Zhao, T. Rajh, L. Zang, Environ. Sci. Technol. 42 (2008) 308.

[15] L. Yuliati, M. Mazlan, H.O. Lintang, J. Fund. Sci. 7 (2011) 62.

[16] G. Tan, H. Fu, L. Jing, B. Xin, K. Pan, J. Phys. Chem. C. 112 (2008) 3089.

[17] T.-N. Ye, M. Xu, W. Fu, Y.-Y.Cai, X. Wei, K.-X. Wang, Y.N.Zhao, X.-H.Li, J.-S. Chen, Chem. Commun. 50 (2014) 3021. 